\title{
PERCEPCIÓN DE LAS VARIEDADES CULTAS DEL ESPAÑOL POR HABLANTES DEL CENTRO-NORTE DE ESPAÑA SEGÚN LOS DATOS DEL PROYECTO PRECAVES XXI: EL ESPAÑOL EJEMPLAR Y LA VARIEDAD PROPIA
}

\author{
Florentino PAREdes García \\ Universidad de Alcalá \\ Ana M. Cestero Mancera \\ Universidad de Alcalá
}

\section{RESUMEN}

La sociolingüística actual lleva ya tiempo siendo consciente de la necesidad de incorporar nuevos enfoques y nuevas líneas de análisis que permitan una cabal comprensión de los fenómenos analizados, como la incorporación de la perspectiva cognitiva (Moreno Fernández 2012). Una manera de acercarse a ambos aspectos es a través del análisis de creencias y actitudes lingüísticas. Desde esta perspectiva se plantea el proyecto PRECAVES XXI (Cestero Mancera y Paredes García 2015a y 2015b), un proyecto panhispánico de estudio de las actitudes hacia las variedades del español que utiliza la técnica de encuesta mediante pares falsos o matches guise y, además, permite que los informadores evalúen muestras reales de lengua hablada. La hipótesis de la que se parte es que el conocimiento de las creencias y actitudes lingüísticas de los hablantes permite conocer la percepción de los sujetos hacia las variedades y el uso de variantes sociolingüísticas y sociolectales, y, por tanto, informa de patrones sociolingüísticos y geolingüísticos, así como sobre la dirección de los cambios lingüísticos. En este artículo se presenta un avance de los primeros resultados sobre creencias y actitudes de sujetos del centro-norte peninsular en relación con dos aspectos: dónde se habla el mejor español y cómo evalúan su propia variedad.

PALABRAS ClAVE: actitudes lingüisticas, variedades del español, castellano, técnica de pares falsos, lengua ejemplar.

\section{AbSTRACT}

Contemporary sociolinguists have long been aware of the need to incorporate new approaches and lines of analysis, such as cognition (Moreno Fernández 2012), in order to gain a full understanding of the phenomena studied. One way 
to address both questions is through a linguistic analysis of beliefs and attitudes. Such is the aim of the pan-Hispanic PRECAVES XXI project (Cestero Mancera \& Paredes García 2015a y 2015b), which comprises a study of perceptions and attitudes regarding varieties of Spanish based on a questionnaire using false pairs or matched-guise pairs and also allows informants to evaluate real samples of spoken language. The hypothesis is that information about speakers' linguistic beliefs and attitudes will yield knowledge about subjects' perceptions of varieties and the use of sociolinguistic and sociolectal variants, and also therefore about sociolinguistic and geolinguistic patterns and the direction of linguistic changes. In this communication, we present a brief summary of the project methodology together with some of the results obtained on the beliefs and attitudes of subjects from the central north of Spain regarding official varieties of Spanish, and more specifically, about their own variety. These results indicate that the overall assessment of all the varieties analysed is positive, especially as regards the affective component, and that the Andalusian variant presents the greatest differences in assessment, possibly because it is perceived as the most divergent.

KEYWORDS: language attitudes, varieties of Spanish, Castilian, Matched Guise Technique, exemplar language.

\section{INTRODUCCIÓN ${ }^{1}$}

El interés por las actitudes lingüísticas ha ido creciendo en las últimas décadas, entre otras razones porque su conocimiento se ha revelado de capital importancia para explicar las complejas relaciones que se producen entre la sociedad y el uso del lenguaje. La percepción de los hechos lingüísticos y su correspondiente evaluación son, en palabras de Edward (2011), una especie de ventana desde la que puede observarse la vida social. De ahí que hayan sido muchas disciplinas, y no solo las directamente relacionadas con la lingüística, las que se han interesado por su estudio, y que los hallazgos hayan podido aplicarse a diversas esferas de la vida pública, como la política y la planificación lingüísticas, la educación o la economía. No obstante, y a pesar de la importancia que se concede a este asunto y del creciente número de estudios que se ocupan de ello, todavía hoy se carece

${ }^{1}$ Este trabajo se inscribe en los proyectos de investigación «Estudio complementario de los patrones sociolingüísticos y los procesos de integración sociolingüística en el español de Madrid» (Ref. FFI2015-68171-C5-4-P), financiado por el Ministerio de Economía y Competitividad de España, y «La población migrante de la comunidad de Madrid: estudio multidisciplinar y herramientas para la integración sociolingüística - IN.MIGRA2-CM» (ref. H2015/HUM3404), financiado por la Comunidad de Madrid con ayudas del Fondo Social Europeo. 
de muchos conocimientos sobre el funcionamiento de las creencias y las actitudes, así como de sus repercusiones.

En el presente artículo se abordan dos de los aspectos desarrollados en el Proyecto para el estudio de las creencias y actitudes hacia las variedades del español del siglo XXI (PRECAVES XXI) relacionados con la percepción de las variedades del español:

1) cuáles tienen los hablantes del centro-norte de España como mejores y más prestigiosas, $\mathrm{y}$

2) cómo perciben su propia variedad.

Para ello, se han analizado cuantitativa y cualitativamente las respuestas al cuestionario de una muestra de 83 sujetos, pertenecientes a grupos o colectivos que han sido objeto de especial atención en la fase inicial de este proyecto por estar directamente relacionados con la lengua española y/o su enseñanza. Se trata de estudiantes de carreras universitarias del ámbito de la filología o la Lingüística y de estudiantes de másteres orientados a la formación como profesores de lengua española. Conocer la percepción que estos hablantes tienen de la lengua y las actitudes que muestran hacia las variedades es de suma importancia para la visión que se ofrezca de la lengua y sus variedades y, a la vez, puede dar valiosa información sobre la persistencia de estereotipos o prejuicios vinculados a algunas variedades.

\section{MARCO TEÓRICO: CREENCIAS Y ACTITUDES SOCIOLINGÜÍSTICAS}

La causa última de la variación lingüística hay que buscarla en el modo en que se perciben los hechos lingüísticos, dado que la conducta lingüística, como han apuntado entre otros López Morales (1989) y Moreno Fernández $(2005,2012)$, está regida por creencias y actitudes individuales y sociales. Mediante ellas, los hablantes aprueban o desaprueban tanto los usos concretos como las variedades lingüísticas, sean estas de una misma lengua, sean las que se forman por contacto interlingüístico, e incluso a los propios usuarios de esas variedades (Edward 2011).

En la bibliografía sobre las actitudes se pueden distinguir dos concepciones contrapuestas: la primera, la mentalista, considera que la actitud consiste en una disposición mental del individuo que, en función de sus experiencias personales, le lleva a responder de un modo determinado ante los objetos y las situaciones (Allport 1935, Williams 1974, Gardner 1982 y 1985 , Ajzen 1988); la segunda, la conductista, entiende la actitud como la acción observable que surge como reacción al estímulo (Osgood y Tannenbaum 1957, Fishbein 1965). Ambos modelos divergen en la posibilidad de observar directamente la actitud y, por tanto, en su capacidad para predecir el 
comportamiento humano; además, frente a la concepción conductista de la actitud como unidad indivisible, los modelos teóricos mentalistas conciben la actitud como el constructo resultante de la combinación de tres componentes: el cognoscitivo o cognitivo (pensamientos y creencias en relación con un estímulo), el afectivo (valoraciones, emociones y sentimientos relativos al estímulo) y el conductual o conativo (comportamiento ante el estímulo).

La actitud lingüística, siguiendo a López Morales (1989), está dominada por el rasgo conativo, por lo que puede analizarse a partir de la acción o reacción misma ante el hecho lingüístico - esto es, el uso o desuso de una variante, de una variedad o de una lengua-, que se produce por influencia de las creencias, favorables o adversas, hacia el hecho en cuestión. Tales creencias provienen de los conocimientos lingüísticos y sociolingüísticos fundados o infundados del hablante, es decir, de su conciencia sociolingüística -dimensión cognoscitiva-, o de percepciones y consideraciones relacionadas con la afectividad del propio hablante y de su comunidad de habla. En base a tal perspectiva, el engranaje sociolingüístico del binomio creencias-actitudes puede resumirse de la manera que sigue: el conocimiento sobre cómo funciona en una comunidad de habla un hecho lingüístico, así como la percepción afectiva hacia él por parte de los miembros de esa comunidad, puede originar creencias sobre ese hecho. Si estas son positivas, confieren estatus al hecho lingüístico y pueden provocar una actitud favorable en el individuo, que consecuentemente lo acepta y lo emplea; si las creencias son negativas, el hecho lingüístico se estigmatiza, dando como resultado la aparición de actitudes desfavorables que impiden que los miembros de la comunidad lo hagan suyo.

Esta concepción, ecléctica, permite el estudio empírico de las actitudes sociolingüísticas a partir de las percepciones y creencias de los individuos acerca de los hechos lingüísticos, que tienen que ver con el conocimiento que poseen de ellos -componente cognoscitivo: conciencia sociolingüística basada en el prestigio abierto, social y lingüístico- y con la afectividad hacia ellos -componente afectivo: sentimientos provenientes de prestigios psicosociales abiertos o encubiertos, que se relacionan con gustos, identidad, solidaridad, lealtad, etc.-. El procedimiento metodológico para su estudio estará basado en valoraciones directas e indirectas de los hechos lingüísticos, que nos informan de la predisposición del hablante a utilizar o no el fenómeno lingüístico examinado, sea una variante de una variable, una variedad lingüística o una lengua en situación de contacto con otra u otras, o de la predisposición del hablante a enseñar o aprender una variedad o una lengua segunda o extranjera.

Los trabajos realizados hasta el momento han pretendido conocer las percepciones de los individuos hacia usos sociolingüísticos concretos y, especialmente, hacia las lenguas utilizadas en comunidades bilingües o pluri- 
lingües (Gómez Molina 1998, 2012, cf. también la bibliografía en Cestero y Paredes 2015a). Son menos los estudios que se centran en las percepciones y creencias de distintos grupos sociales o comunidades acerca de las variedades de una misma lengua, así como de las actitudes que provocan (López Morales 2001, Quintanilla 2012 y Chiquito y Quesada [eds.] 2014), y de su incidencia en ámbitos concretos de gran desarrollo, tales como la enseñanza y adquisición de lenguas segundas y extranjeras (Sancho Pascual 2014). En relación con las variedades del español, en la actualidad se están llevando a cabo dos proyectos planteados con pretensiones de alcance panhispánico: el proyecto LIAS (Linguistic Identity and Attitudes in Spanish-speaking Latin America), dirigido por Miguel Ángel Quesada y Beatriz Chiquito (Chiquito y Quesada 2014), y el proyecto PRECAVES XXI ( «Proyecto para el estudio de las creencias y actitudes hacia las variedades del español del siglo XXI»), coordinado desde la Universidad de Alcalá (España) (Cestero y Paredes 2015a, 2015b). Metodológicamente se trata de proyectos muy diferentes, pues mientras que el primero se sirve de técnicas directas de medición de actitudes y recurre al cuestionario únicamente, en el PRECAVES XXI se emplean técnicas directas e indirectas de medición de actitudes, como se explicará en el apartado 2.

\section{MetOdOlOGía DEL PROYECTO PRECAVES XXI}

El «Proyecto para el estudio de las creencias y actitudes hacia las variedades del español en el siglo XXI» (PRECAVES XXI) nace con el objetivo de avanzar en el conocimiento de las percepciones de los individuos acerca de la lengua y sus variedades, y específicamente, conocer las creencias y actitudes de distintos grupos de individuos en relación con la norma culta urbana hablada de las principales áreas geolectales del español, es decir, aquellas variedades que sirven como modelo idiomático para los hispanohablantes en sus respectivas zonas. El proyecto emplea una metodología específica, que se presentará brevemente a continuación, y ha empezado ya a dar frutos (Cestero y Paredes 2015a, 2015b). Desde la posición ecléctica antes señalada, se ha diseñado una prueba que, partiendo de la técnica de pares falsos o máscaras (Lambert 1967; Lambert y colaboradores 1960, 1968), permite obtener de forma directa e indirecta información sobre la percepción que los individuos tienen de las variedades estudiadas y, consecuentemente, de sus actitudes hacia ellas.

En esta fase inicial del proyecto, se ha priorizado trabajar con determinados colectivos que se consideran influyentes en las direcciones de prestigios sociolingüísticos, así como en la enseñanza y la adquisición de lenguas segundas y extranjeras. Por ello, en la etapa inicial, se han aplicado las encuestas a personas pertenecientes a los siguientes grupos: 
1) estudiantes de Filología o Lingüística sin conocimientos básicos sobre variedades del español (entendiendo por tales a quienes no han cursado asignaturas relacionadas con la sociolingüística o la dialectología del español),

2) estudiantes de Filología o Lingüística con conocimientos básicos sobre variedades del español (es decir, que hayan cursado asignaturas relacionadas con la sociolingüística o la dialectología) y

3) estudiantes de posgrado que se especializan en la enseñanza de español como lengua extranjera.

En la actualidad, se están recogiendo datos de todo el dominio de habla hispana por zonas generales, estableciendo como tales las ocho correspondientes a las consideradas como de influencia de variedades normativas del español, a saber, centro y norte de España, sur de la Península Ibérica, Canarias, México y Centroamérica, Caribe, Andes, Chile y Río de la Plata (Moreno Fernández 1993, 2000 y 2009; Moreno Fernández y Otero Roth 2007). Se está trabajando ya en el proyecto de manera coordinada, de forma que cada equipo PRECAVES XXI recoge y estudia muestras de su zona.

Para el estudio de las creencias y actitudes en relación con las variedades normativas del español en el siglo XXI se ha diseñado una encuesta que se estructura en tres partes:

1) datos sociológicos del encuestado,

2) grabaciones $\mathrm{y}$

3) cuestionarios.

Con objeto de tener la información necesaria para interpretar los datos que se ofrecerán en este trabajo, se resumen aquí las principales características de la investigación (para más detalles vid. Cestero y Paredes 2015a y 2015b).

Los datos sociológicos a los que se atiende, por su posible incidencia en las creencias y actitudes sociolingüísticas, son los siguientes: el sexo, la edad, el nivel de estudios, la profesión y la lengua materna. Para el establecimiento de grupos sociales, seguimos los criterios de intervalos establecidos en el Proyecto para el estudio sociolingüístico del español de España y América (PRESEEA) (Moreno Fernández 1996, PRESEEA 2008, Cestero, Molina y Paredes 2012). Los datos sociogeográficos que se recogen, también por su implicación en las valoraciones y comportamientos del individuo, tienen que ver con el país de nacimiento del encuestado y su grado de exposición a las variedades de la lengua española. Para conocer este segundo aspecto, se le pide información al sujeto acerca de los viajes por países hispanohablantes y no hispanohablantes, la frecuencia de sus viajes a otros países (hispanohablantes y no hispanohablantes) y la exposición al español difundido por los medios de comunicación (en concreto se indaga sobre el número de horas diarias que ve televisión y que consulta internet). 
En cuanto a las grabaciones, el procedimiento ideado para la recogida de datos y la medición de actitudes parte, como se ha mencionado con anterioridad, de la técnica de pares falsos o de máscaras (matched guise technique). La recogida de material para estudio se basa en la escucha de dieciséis grabaciones -la mitad de discurso oral y la otra mitad de lectura de un texto escrito-, pertenecientes a ocho locutores, hombres adultos o mujeres adultas de entre 34 y 54 años, con nivel de estudios superior, de cada una de las variedades cultas con las que trabajamos: castellana, andaluza, canaria, mexicana y centroamericana, caribeña, andina, chilena y rioplatense. Así, en total, la encuesta dispone de dos grabaciones de voz de cada locutor, una en la que, siguiendo a López Morales (1979), habla durante unos dos minutos sobre los problemas que ocasiona el tráfico en las grandes ciudades, y otra en la que lee durante un minuto un texto sobre la vivienda ( $c f$. Sancho 2014). Cada encuestado evalúa solo voces masculinas o solo femeninas, pero todos siguen idéntica pauta: en las 16 audiciones se alterna sucesivamente discurso oral y discurso escrito y se van alternando las ocho variedades estudiadas, de forma que nunca aparecen seguidas las dos grabaciones del mismo locutor.

Por último, la entrevista presenta, como herramienta fundamental de obtención de datos, la realización de un cuestionario, de preguntas directas e indirectas, abiertas y cerradas y, en su mayoría, con escalas de diferencial semántico, con el que se pretende obtener información sobre valoraciones y percepciones de los informantes hacia las variedades del español y, con ello, sobre las actitudes previsibles hacia las mismas (<http://www.varieda desdelespanol.es $>$ ). Para cada una de las 16 audiciones, el proyecto ha previsto un cuestionario idéntico, compuesto por doce preguntas que giran en torno a tres dimensiones: valoración directa de la variedad que escuchan, valoración de la variedad a través de la persona que habla o lee y valoración de la variedad a través de la zona geográfica y de la cultura a la que el encuestado cree que corresponde el locutor de la audición.

\section{CREENCIAS Y ACTITUdES HACIA LAS VARIEDADES DEL ESPAÑOL: PERCEPCIONES} DE LOS HABLANTES DEL CENTRO-NORTE PENINSULAR

Como parte del proyecto coordinado PRECAVES XXI, los diversos equipos han comenzado a analizar las creencias y actitudes de los hablantes de las respectivas áreas hacia su propia variedad de español. Para la zona centro-norte peninsular se analizan los datos correspondientes a 83 encuestas, de las cuales 51 pertenecen a personas nacidas en la Comunidad de Madrid, 19 en Castilla-La Mancha, 7 en Castilla-León, 3 en el norte de Extremadura, 2 en el País Vasco y 1 en La Rioja.

La distribución de la muestra por sexo está claramente descompensada hacia el grupo femenino -19 hombres y 64 mujeres-, en consonancia con 
el predominio de las mujeres en la composición del alumnado de Filología. En cuanto a la edad, se dispone de información de dos generaciones, que tampoco presenta equilibrio en la distribución de la muestra: 20 son menores de 20 años y 63 tienen entre 20 y 34 años; no se ha contado con informantes de 35 años o más, en esta ocasión, por trabajar con estudiantes. Los hablantes corresponden a dos niveles de estudios, 11 de ellos tienen estudios secundarios terminados y 72 estudios universitarios. Según el grupo al que pertenecen los sujetos, hay 47 estudiantes de Filología que no han estudiado asignaturas relacionadas con la variación del español, 22 que sí lo han hecho y 14 profesores de español (estudiantes de máster).

FIgURA 1. Muestra

\begin{tabular}{|c|c|c|}
\hline \multirow{2}{*}{ Sexo } & hombres & 19 \\
\hline & mujeres & 64 \\
\hline \multirow{2}{*}{ Edad } & menores de 20 años & 20 \\
\hline & entre 20 y 34 años & 63 \\
\hline \multirow{5}{*}{ Profesión } & estudiantes & 65 \\
\hline & profesores & 5 \\
\hline & empleados medios & 4 \\
\hline & obrero cualificado & 1 \\
\hline & $\mathrm{s} / \mathrm{d}$ & 8 \\
\hline \multirow{6}{*}{$\begin{array}{l}\text { Comunidad } \\
\text { de origen }\end{array}$} & Madrid & 51 \\
\hline & Castilla-La Mancha & 19 \\
\hline & Castilla y León & 7 \\
\hline & Extremadura & 3 \\
\hline & País Vasco & 2 \\
\hline & La Rioja & 1 \\
\hline \multirow{4}{*}{ Colectivo } & Estudiantes sin formación dialectal & 47 \\
\hline & Estudiantes con formación dialectal & 22 \\
\hline & Estudiantes del máster para profesores de español & 14 \\
\hline & TOTAL & 83 \\
\hline
\end{tabular}

Sobre esta muestra, en el presente artículo se van a estudiar los dos aspectos que se han señalado en la introducción:

1) qué variedades consideran los sujetos del centro-norte peninsular como mejores y más prestigiosas y

2) qué percepción tienen acerca de la variedad propia o más cercana, la castellana. 


\subsection{El prestigio de las variedades: consideraciones de hablantes del centro-norte de España}

Las creencias y actitudes lingüísticas de un individuo están directamente vinculadas con su ideología lingüística, consistente en el conjunto de creencias acerca de la lengua, el lenguaje, las variedades lingüísticas y los hablantes que las usan. Según del Valle y Gabriel-Stheeman (2002), la cultura lingüística occidental -y la hispánica forma parte de ella-, puede caracterizarse como monoglósica, dada la preferencia de los hablantes por el monolingüismo o el monodialectalismo y por su renuencia o rechazo a la variedad o la diversidad. Este rasgo se manifiesta a través de creencias que otorgan gran importancia a la unidad idiomática y a la corrección idomática, y afecta también a aspectos como la similitud entre variantes o la relación afectiva hacia los distintos usos lingüísticos (Rojas y Avilés 2013). En opinión de muchos hablantes, las realizaciones de una lengua en diferentes áreas geográficas no son equivalentes, sino que las de unos territorios son «mejores» que las de otros, lo que permitiría ordenar las variedades lingüísticas cualitativamente en una escala jerárquica según la que unas variedades representan mejor que otras el modelo ideal de lengua.

Este tipo de creencia (o, mejor, este estereotipo) está extendido entre los hablantes comunes, pero interesa saber qué es lo que ocurre con quienes están especializados en el estudio de la lengua española o tienen intención de especializarse. Se analizan, para ello, los datos correspondientes a la pregunta acerca de dónde consideran que se habla mejor el español, tal como se recoge en la Figura 2.

FIGURA 2. Respuestas sobre la región o zona en la que se habla mejor el español

\begin{tabular}{lcc}
\cline { 2 - 3 } & Frecuencia & Porcentaje \\
\hline Castilla & 47 & 56,6 \\
\hline España & 1 & 1,2 \\
\hline Hispanoamérica & 2 & 2,4 \\
\hline Otras & 2 & 2,4 \\
\hline En todas por igual & 25 & 30,1 \\
\hline No contesta & 6 & 7,2 \\
\hline Total & 83 & 100 \\
\hline
\end{tabular}

Excluidos quienes no contestan, podemos dividir al resto de la muestra en dos grupos: el de aquellos que consideran que hay una jerarquía de 
variedades y el de quienes consideran que tal jerarquía no existe. El grupo más numeroso es el primero, que suma el 62,6\% de la muestra. Hay que deducir, por tanto, que la percepción general de los hablantes originarios de las áreas central y septentrional de España es que no todas las variedades son equivalentes, sino que hay unas que prototípicamente representan mejor que otras la lengua española.

Para más de la mitad de la muestra, el mejor español se identifica con la variedad propia. En 47 de las 83 encuestas se selecciona la variedad castellana como modelo idiomático, lo que equivale a decir que el 56,6\% de los hablantes otorga el máximo prestigio lingüístico a esta variedad lingüística. Las regiones o comunidades autónomas españolas más citadas en este punto son «Castilla y León», que se cita en once ocasiones, y «Castilla», sin más precisión, que aparece cuatro veces; son nombradas una vez «Castilla la Nueva», la «Comunidad de Madrid»y, lo que constituye una respuesta algo menos esperable, «Extremadura». Algunos encuestados eludieron senalar una comunidad autónoma específica y se refirieron de forma más genérica al «centro de España», citado por cuatro encuestados, a la «zona septentrional», citada por dos, o simplemente a «España», una vez ${ }^{2}$.

Llama la atención la ausencia de referencias directas a otras variedades de español de España, como el andaluz o el canario, así como la escasez de menciones de las variedades americanas. Solo dos encuestados consideran que el mejor español se sitúa en «América» o, como uno de ellos precisa, en «Sudamérica» y el único país citado en este punto es «Colombia».

En este estudio no se han encontrado grandes novedades tampoco en lo que se refiere a las ciudades en las que los hablantes sitúan el modelo de español. En el reducido número de las que aparecen explícitamente señaladas como modelo idiomático solo se encuentran ciudades ubicadas en las dos Castillas: «Madrid», citada diez veces; de la comunidad castellanoleonesa aparecen «Valladolid», cuatro veces, «Burgos», «León» y «Soria»; entre las ciudades de la región castellano-manchega solo aparece «Guadalajara». Uno de los encuestados señala de manera más amplia que el español más prestigioso se sitúa en las variedades urbanas, si bien todos los nombres de las que cita se sitúan en la zona centro-septentrional de España: «En las grandes ciudades españolas: Madrid, Barcelona, Bilbao, Valencia, Zaragoza y en las dos Castillas».

${ }^{2}$ Los resultados del proyecto LIAS en este sentido, con una muestra de 400 madrileños que incluyen a todos los grupos sociales, presentan notorias diferencias: Castilla y Madrid son las regiones que hablan «mejor», con un 42,5\% cada una de ellas; quienes creen que en ninguna se habla mejor solo alcanzan el 2,8\% (Yraola 2014). Hay que tener en cuenta, no obstante, que la formulación de la pregunta podía inducir a los encuestados a comparar su propia variedad con otras, no a establecer una jerarquía abstracta de variedades. 
Frente a las ideas anteriores, que establecen una jerarquía entre las variedades del español, aproximadamente un tercio de los encuestados considera que ninguna de ellas prevalece sobre el resto. Esta creencia aparece formulada con expresiones en positivo («En todas por igual», «Todas») o en negativo («En ninguna zona», «No existe una región o zona donde se hable mejor español», "En ninguna, solo son distintas variedades de la lengua»). Algunos encuestados argumentan algo más su opinión, entre ellos quienes matizan que en todas las regiones se habla bien («En todas se habla un español igualmente bueno»). También se alude directamente a la corrección como criterio de evaluación, desarrollando implícitamente la igualdad mejor = más correcto ( «En cualquier zona hispanohablante puede hablarse correctamente el español»). Son numerosos los testimonios que reconocen la existencia de la diversidad ( Caada zona tiene sus particularidades», «No me gusta generalizar, cada cual con su idiosincrasia»), pero ese reconocimiento no implica preeminencia de ninguna de las variedades ( «Son dialectos diferentes, no hay mejores ni peores. Cada zona presenta unos rasgos propios», «En ninguna zona se habla mejor que en otra, simplemente hay distintas variedades», "No creo que haya una zona donde se hable el "mejor español”», «Cada zona tiene sus características», «No se habla mejor o peor el español por zonas, sino que cada zona tiene su variedad», «No creo que haya una zona donde se hable mejor el español. Cada región puede tener su variedad y no por ello ser peor», «En cada zona se habla diferente, ni mejor ni peor», "No se habla mejor, se habla diferente», «Son dialectos diferentes, no hay mejores ni peores», «El español no se habla mejor o peor, sino que presenta diferentes variedades lingüísticas de gran riqueza dialectal»).

Se puede ver también si hay algún tipo de relación entre esta creencia y características sociológicas de los encuestados. Los resultados generales se recogen en la Figura 3 (ver página siguiente), en la que los resultados se agrupan según la creencia de los encuestados sobre la existencia de relación jerárquica o igualitaria entre las variedades.

Como se ve en la Figura 3, no se han traducido en diferencias estadísticamente significativas las diferencias en los grupos según el sexo y el colectivo al que pertenece el informante ${ }^{3}$. En cambio, los factores que condicionan la opinión acerca de la variedad más prestigiosa son la edad y el origen geográfico de los sujetos.

\footnotetext{
${ }^{3}$ Que el factor «colectivo al que pertenece el encuestado» no haya sido relevante puede deberse a que solo en los dos primeros grupos hay gradación en lo que se refiere a la formación y el conocimiento sobre variedades. En cambio, el grupo de quienes estudian el máster de ELE está formado por estudiantes de orígenes diversos e incluso de carreras diferentes, por lo que su formación en este sentido no es homogénea.
} 
FIGURA 3. Creencias acerca de la existencia de jerarquía entre variedades según factores sociales

\begin{tabular}{l|l|r|r|r|c}
\hline \multicolumn{2}{l|}{ Factor } & \multicolumn{2}{|c|}{ Jerarquía } & \multicolumn{2}{c}{ Igualdad } \\
\hline \multicolumn{2}{l|}{$($ Significación $)$} & $\mathrm{N}$ & $\%$ & $\mathrm{~N}$ & $\%$ \\
\hline Sexo & $\mathrm{H}$ & 9 & 42,1 & 8 & 42,1 \\
$(\mathrm{p}=0,523)$ & $\mathrm{M}$ & 43 & 60,9 & 17 & 26,6 \\
\hline \multirow{3}{*}{ Colectivo } & Grado sin formación & 31 & 65,9 & 14 & 29,8 \\
$(\mathrm{p}=0,610)$ & Grado con formación & 13 & 59,0 & 6 & 27,3 \\
& Máster profesores & 8 & 57,1 & 5 & 35,7 \\
\hline \multirow{2}{*}{ Edad } & <20 años & 19 & 95,0 & 1 & 5,0 \\
$(\mathrm{p}=0,004)$ & 20-34 años & 33 & 52,4 & 24 & 38,1 \\
\hline \multirow{3}{*}{ Origen } & Madrid & 26 & 51,0 & 22 & 43,1 \\
$(\mathrm{p}=0,001)$ & Castilla-La Mancha & 13 & 68,5 & 3 & 15,8 \\
& Castilla y León & 7 & 100 & 0 & 0 \\
& Extremadura & 1 & 100 & 0 & 0 \\
& La Rioja & 3 & 100 & 0 & 0 \\
& País Vasco & 2 & 100 & 0 & 0 \\
\hline
\end{tabular}

Cuando se consideran la variable generacional, los resultados estadísticos muestran que la edad de los sujetos condiciona su opinión relativa a la variedad prestigiosa $\left(\chi^{2}=17,028 ;\right.$ g.1. $\left.5 ; \mathrm{p}=0,004\right)$. Entre los más jóvenes prácticamente hay unanimidad respecto a la supremacía de la variedad castellana (90,0-95\% si incluimos la respuesta «España»), mientras que en el grupo de entre 20 y 34 quienes mantienen esa misma opinión no alcanza la mitad porcentual (46,0\%). Entre este segundo grupo, en cambio, un 38,1\% considera que no hay ninguna variedad de español que pueda considerarse mejor que otra. Respecto a esta variable para la explicación completa de los datos hay que tener en cuenta que en el grupo más joven se encuentran solo los estudiantes que no han concluido el primer curso de estudios universitarios y, por tanto, ninguno de ellos ha recibido formación específica acerca de las variedades del español.

También el origen geográfico del hablante influye en la creencia acerca de cuál es la variedad más prestigiosa $\left(\chi^{2}=51,277\right.$; g.l. 25, p =0,001). El análisis de estos datos permite ver que en todos los grupos, excepto en el de los madrileños, la mitad o más considera que la variedad castellana es la que mejor representa el modelo idiomático. Esta opinión resulta categórica en el caso de los castellano-leoneses: los siete hablantes de este origen 
afirman la primacía de su propia variedad. Los madrileños, en cambio, se muestran como el grupo más permeable: por una parte, los que vinculan el prestigio al castellano no alcanzan a la mitad porcentual de la muestra; por otra, es el grupo que más admite la equivalencia de todas las variedades lingüísticas.

Se pueden, por tanto, extraer algunas conclusiones en relación con las creencias acerca de la variedad modélica de los hablantes del centro-norte peninsular. La primera es que incluso entre este tipo de hablantes más especializado a los que ha atendido la muestra se mantiene la creencia de que hay diferencias entre las variedades del español y que unas pueden considerarse más ejemplares que otras. Como era de esperar, la variedad mejor valorada es la castellana, así que hay que concluir que la autopercepción de la propia variedad es muy positiva. Los madrileños son los que se muestran más eclécticos y más permeables a admitir el resto de variedades, frente a la unanimidad de los castellano-leoneses en valorar su propia variedad como ejemplar o prototípica. No obstante, es también elevado el número de quienes consideran la equivalencia dialectal, al menos en el nivel culto que es el que aquí se considera: uno de cada tres encuestados considera que no se puede establecer jerarquía entre las variedades. Esta creencia parece aumentar con la edad y con el hecho de haber recibido formación sobre los dialectos del español.

\subsection{Percepciones de hablantes del centro-norte peninsular sobre la variedad castellana}

Como se ha mencionado ya, se ha analizado un total de 83 encuestas, realizadas por hablantes del centro-norte peninsular y, por tanto, con dicha variedad adquirida ${ }^{4}$. Prácticamente todos ellos han identificado correctamente su variedad en las audiciones, o bien respondiendo Madrid, Castilla, Castilla y León, centro (peninsular), etc., o bien anotando España, dando por sentada una asociación directa entre la variedad centro-norte

\footnotetext{
4 En el total de las 83 encuestas analizadas, los informantes han valorado 1336 locuciones de hablantes originarios de ocho áreas del español. De ellas, han identificado, acertada o erróneamente, como del área castellana 125 y como españolas en general, 100. Las variedades que han confundido con la centro-norteña peninsular han sido la andaluza (8 casos), la chilena (3 casos), la canaria, la mexicana y la rioplatense (1 caso cada una); por otro lado, las grabaciones consideradas como de «España» que no son de sujetos del centro y norte peninsular corresponden a la variedad andaluza (28 casos), a la canaria (16 casos), a la chilena ( 5 casos), a la andina ( 2 casos) y a la caribeña (1 caso). Como puede verse, las confusiones se producen, fundamentalmente, entre variedades próximas geográficamente y, por tanto, con las que los informantes pueden tener más contacto, o entre variedades valoradas positivamente o menos identificables, como puede ser la chilena.
} 
de la Península y la propia Península; excepcionalmente, tres informantes relacionan la variedad que oyen con el sur peninsular, si bien dos de ellos apuntan, además, centro y España.

El grado de identidad que muestran los informantes con la pronunciación propia permite conocer datos que podrían explicar las valoraciones que efectúan. A pesar de que todos los sujetos de la muestra tienen, en principio, la variedad del centro-norte peninsular, un $14,4 \%$ no considera que la variedad que ha oído, la del centro peninsular, sea idéntica o similar a la suya $(2,4 \%$ la consideran totalmente diferente, $5,4 \%$ la consideran bastante diferente, $6,6 \%$ la consideran ligeramente igual); los informantes de Extremadura (5 casos) y de Guadalajara (8 casos) son los que han indicado un grado de identidad más bajo, aunque también lo han hecho varios madrileños (5 casos), algún alcalaíno ( 2 casos), algún abulense (un caso), algún toledano (un caso) y algún vallisoletano (2 casos). No obstante, la mayoría de los informantes, el 83,7\%, la considera ligeramente diferente (3\%), bastante igual $(34,9 \%)$ o totalmente idéntica $(45,8 \%)$, ya se trate de sujetos de Madrid, de Castilla-León, de Castilla-La Mancha, de La Rioja o del País Vasco. Estos datos constatan que la mayoría de los sujetos de la muestra tiene conciencia geolingüística y, además, la percepción como diferente de la variedad extremeña por parte de los propios hablantes extremeños, a pesar de tratarse de la de sujetos del norte de la comunidad, más cercanos, lingüísticamente hablando, al centro-norte peninsular que al sur. Pasamos a detallar la percepción que han mostrado los informantes del centro-norte peninsular hacia su propia variedad.

\subsubsection{Valoración directa de la variedad del centro-norte de España}

La valoración directa de la variedad centro-norteña de España, por parte de hablantes de esta zona peninsular, ofrece datos diversos que resultan de interés. En principio, se ha documentado una valoración general positiva, ya que la media hallada en las respuestas correspondientes del cuestionario es superior a 3, punto intermedio de la escala de seis grados empleada, si bien no cada media específica supera ese punto (media correspondiente a aspectos afectivos: 3,67, y media relativa a aspectos cognoscitivos: 2,84).

Estos datos han de ser matizados y comentados con algo más de detalle, pues resulta sorprendente que la valoración de los sujetos hacia su variedad sea solo medianamente positiva, y especialmente si tenemos en cuenta que la valoración más baja se produce con respecto a aspectos considerados de carácter cognitivo (afectivamente la valoración es más positiva).

Las características consideradas «afectivas» en el cuestionario con el que trabajamos presentan valoraciones diferentes por parte de los sujetos de la 
FIGURA 4. Valoración directa de la variedad centro-norte peninsular

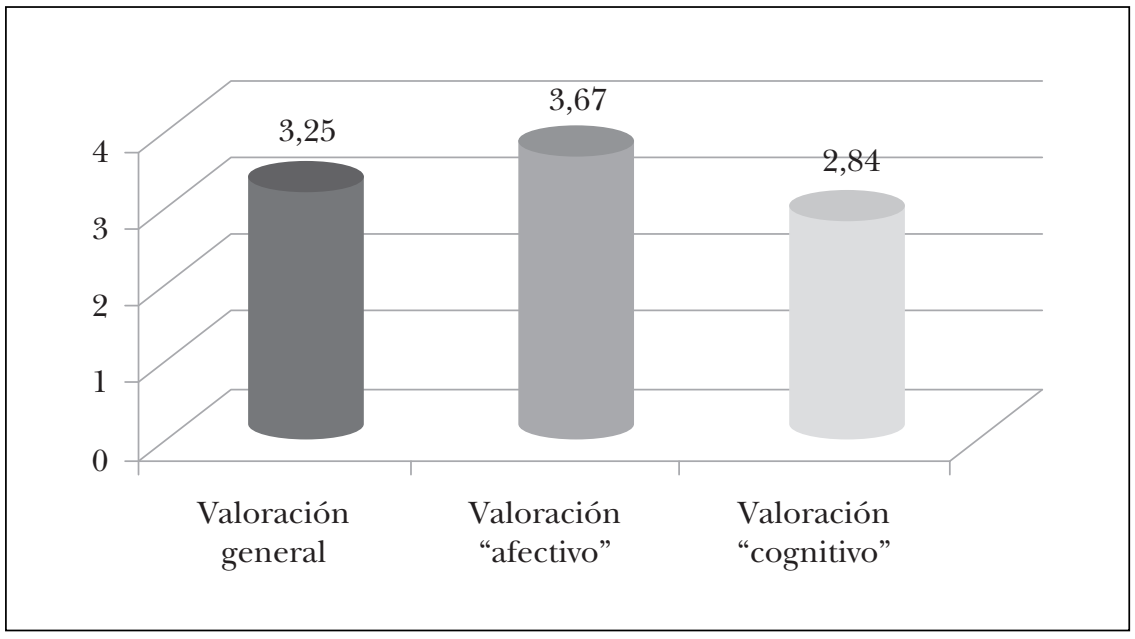

muestra. Así, la variedad es considerada, muy positivamente, como sencilla (media: 4,7), agradable (media: 4,01), cercana (media 3,9), blanda (media: 3,6 ) y bonita (media: 3,57 ), pero no se considera, sin embargo, divertida (media: 2,2). Más diversa es la valoración que hacen los informantes de la variedad a partir de aspectos «cognitivos», pues la consideran áspera (media: 3,58$)$ y monótona (media: 4,65), si bien urbana (media: 4,31), clara (media: 4,2) y lenta (media: 3,80). Estos datos parecen indicar, por tanto, que la valoración es positiva, tanto en lo que concierne a factores afectivos como a cognoscitivos, lo que no impide que los hablantes reconozcan características habitualmente no consideradas positivas de su propia variedad o que, a sabiendas de que se trata de una variedad considerada prestigiosa, intenten rebajar la valoración positiva esperada.

Los aspectos valorados positivamente por hablantes del centro-norte peninsular sobre su propia variedad son, según ellos mismos apuntan, la claridad y la buena pronunciación, si bien también mencionan rasgos como corrección, cercanía o empleo de fonemas determinados $(/ \mathrm{s} /-/ \theta /, / \chi /)$. Y los aspectos de las muestras grabadas valorados negativamente por los sujetos, de manera expresa, han sido la monotonía y la lentitud, además de la pronunciación de algunos sonidos consonánticos, como las sibilantes o la /r/, y la elisión de consonantes finales.

La variable «Tipo de discurso» no ofrece diferencias en las puntuaciones medias globales: oral presenta 3,26 y escrito, 3,25; y tampoco aparecen en las consideraciones de las características cognitivas o afectivas. Sin embargo, la variable «Voz evaluada» sí muestra diferencias que resultan 
cuando menos curiosas, pues la voz masculina obtiene una valoración media $(3,61)$ más alta que la femenina $(3,12)$, y aparece una valoración muy positiva en los rasgos afectivos $(4,04)$ y positiva en los cognitivos $(3,17)$, cuando se valora la voz masculina, mientras que los rasgos afectivos resultan por debajo de la media cuando se evalúa la voz femenina $(2,71)$.

FIGURA 5. Valoración directa de la variedad centro-norte peninsular según la voz del locutor

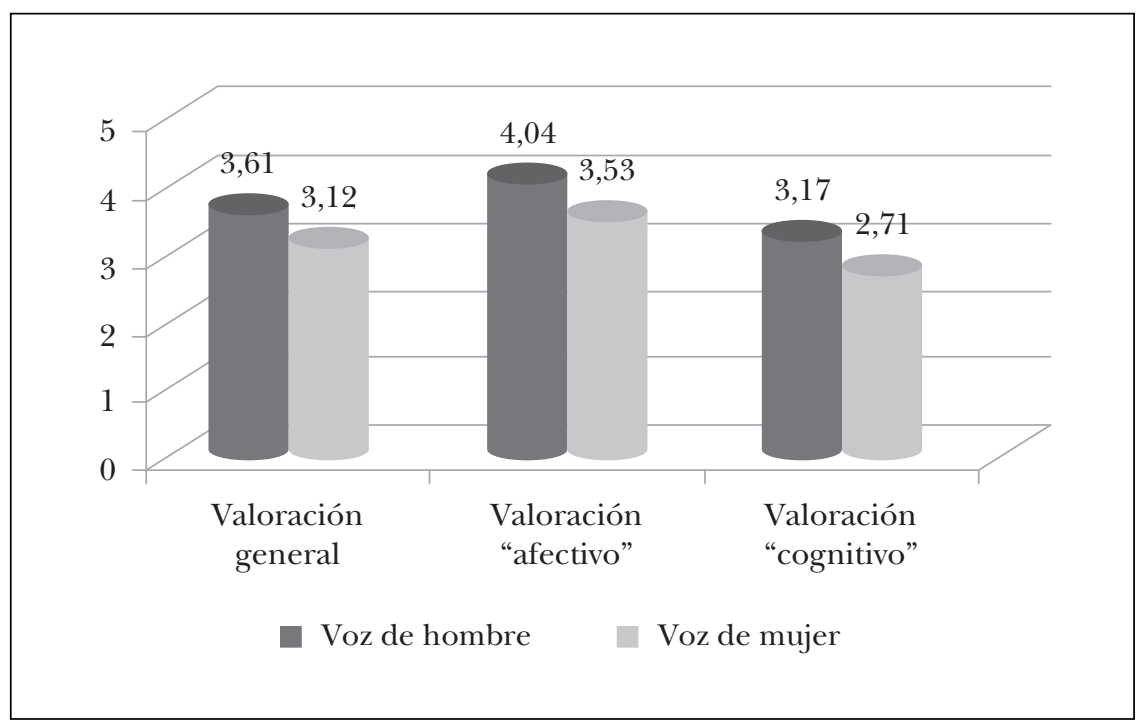

Estos datos podrían relacionarse con el hecho de que, en la muestra, hay más mujeres que hombres (64 frente a 19), que encubren, de alguna manera, la valoración positiva hacia su variedad y hacia voces de personas de su mismo sexo o muestran una conciencia lingüística quizás mayor y menos subjetiva, con una consideración más positiva del habla de los hombres, lo que resultaría contrario a los patrones sociolingüísticos constatados en la gran mayoría de los estudios realizados, o con las características propias de la voz femenina y de la voz masculina que se evalúa (percepciones sobre los propios sujetos que hablan).

Por último, es especialmente significativo el hecho de que sean los sujetos que no han tenido una formación específica sobre variedades del español los que valoren menos positivamente su variedad centro-norteña (3,17 de media: 2,76 con respecto a características de índole cognoscitiva y 3,59 a consideraciones afectivas), y que tal valoración aumente a medida que los informantes acceden al conocimiento o adquieren más instrucción, 
especialmente en lo que al componente cognoscitivo se refiere (estudiantes de grado con conocimientos sobre variedades: 3,21 de media: 2,80 con respecto a características de índole cognoscitiva y 3,61 a consideraciones afectivas; estudiantes de máster: 3,61 de media: 3,19 con respecto a características de índole cognoscitiva y 4,04 a consideraciones afectivas); estos datos constatan que el conocimiento sobre la existencia de variedades de una lengua incide directamente en la percepción que las personas tienen de cada una de ellas.

FigURA 6. Valoración directa de la variedad centro-norte peninsular según el colectivo al que pertenece el encuestado

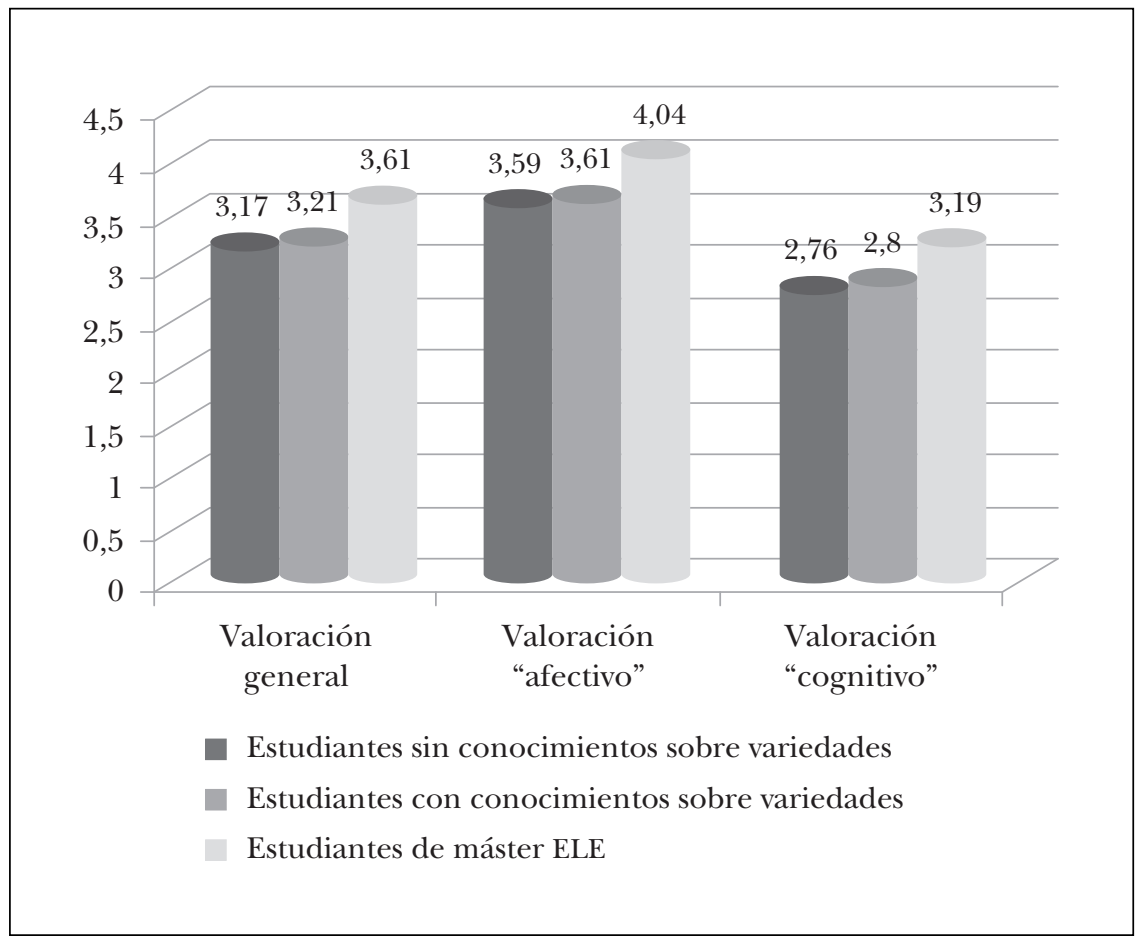

3.2.2 Valoración indirecta de la variedad del centro-norte de España

Las valoraciones indirectas de la variedad del centro-norte peninsular, hacia la persona que habla y hacia la cultura de la persona que habla, obtenidas de la muestra resultan, también, de gran interés. Pasamos a detallarlas y comentarlas. 


\subsubsection{Valoración de la variedad a través de la persona que habla}

La mayoría de los informantes centro-norteños muestran creencias muy positivas respecto a su propia variedad a través de las consideraciones apuntadas sobre el puesto de trabajo (con una media de 2,28 sobre 3, de escala de poco cualificado a altamente cualificado), el nivel de ingresos (con una media de 2,28 sobre 3, de nuevo, de escala de bajo a alto) y el nivel de estudios (3,46 sobre 4, de escala de sin estudios a estudios universitarios) de los sujetos a los que han oído hablar o leer. Así, el 48,2\% de los sujetos considera que la persona que ha escuchado, madrileña, tiene un trabajo bien cualificado, y el 39,8\%, altamente cualificado; el $56 \%$ cree que la persona que ha escuchado tiene ingresos medios y el 35,5\%, que los tiene altos; por último, un 56,6\% de los encuestados apunta que el madrileño o la madrileña que escucha tiene estudios universitarios y un $32,5 \%$, que los tiene secundarios. Las características sociales de las personas del centro-norte peninsular, por tanto, son consideradas altamente positivas.

De nuevo, es más valorada la voz masculina $(3,08)$ que la femenina $(2,53)$, ahora a partir de las características sociales de los hablantes asociadas. Se documenta 1 solo caso en el que se considera poco cualificado al sujeto, hombre, que habla ( 8 en que se considera bien cualificado y 36 , altamente cualificado), y 18 casos en que se atribuye esa característica poco positiva a un sujeto cuando habla una mujer ( 72 en que se considera bien cualificada y 30 , altamente cualificada).

FiguRA 7. Valoración de la variedad a través de las características socioculturales de la persona

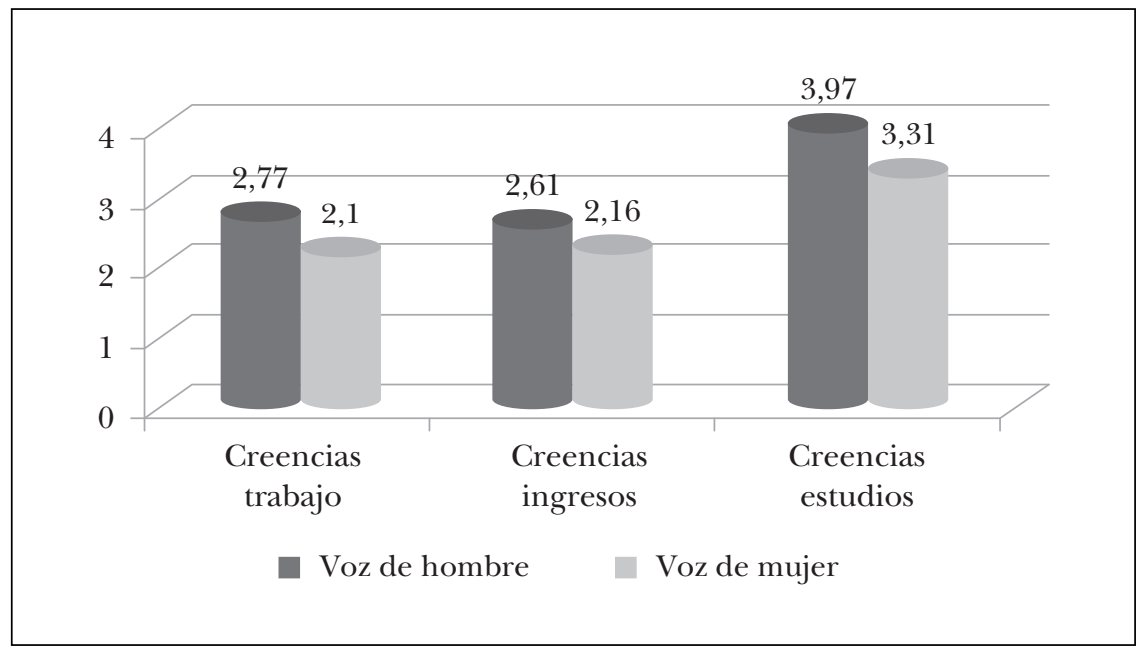


Por otro lado, las características personales de los centro-norteños también son valoradas muy positivamente por los sujetos de la muestra, concretamente con un promedio de 4,21 en una escala de 6. La persona que escuchan, de la Comunidad de Madrid, es considerada, en general, muy educada (4,84 de media), muy inteligente (4,71 de media), muy culta $(4,53$ de media), simpática (3,48 de media) y cercana (3,46 de media). La valoración positiva de la persona que se escucha hablar es apuntada de manera expresa por los sujetos de la muestra al responder a la pregunta que se formula para conocer su opinión sobre las personas de la región o país de los que cree que procede. Como ya comentamos, prácticamente todos los informantes reconocen que la audición con la que ahora trabajamos es de una persona del centro-norte peninsular y se identifican con ella, por eso no sorprende que el $54,2 \%$ de la muestra confiese tener una opinión positiva hacia las personas de la región en cuestión. De manera expresa apuntan que tienen «buena» opinión sobre las personas de la región, que se trata de gente «amable», «amigable», «agradable», «simpática», «alegre», «encantadora», «abierta», «cercana», «cosmopolita», «educada» y «culta», «seria», «sencilla», «sincera»y «honrada».

Una vez más, resulta valorada más positivamente la voz masculina de la encuesta $(4,87$ de media) que la femenina $(3,96)$, ahora con respecto a las características personales que se mencionan. De forma más precisa, se considera que la persona que habla o lee, hombre, es muy educada $(5,6$ de media), muy inteligente (5,5 de media), muy culta (5,3 de media) y simpática (3,9 de media) y cercana (3,9 de media), y que la persona que habla

FIGURA 8. Valoración de la variedad a través de características personales

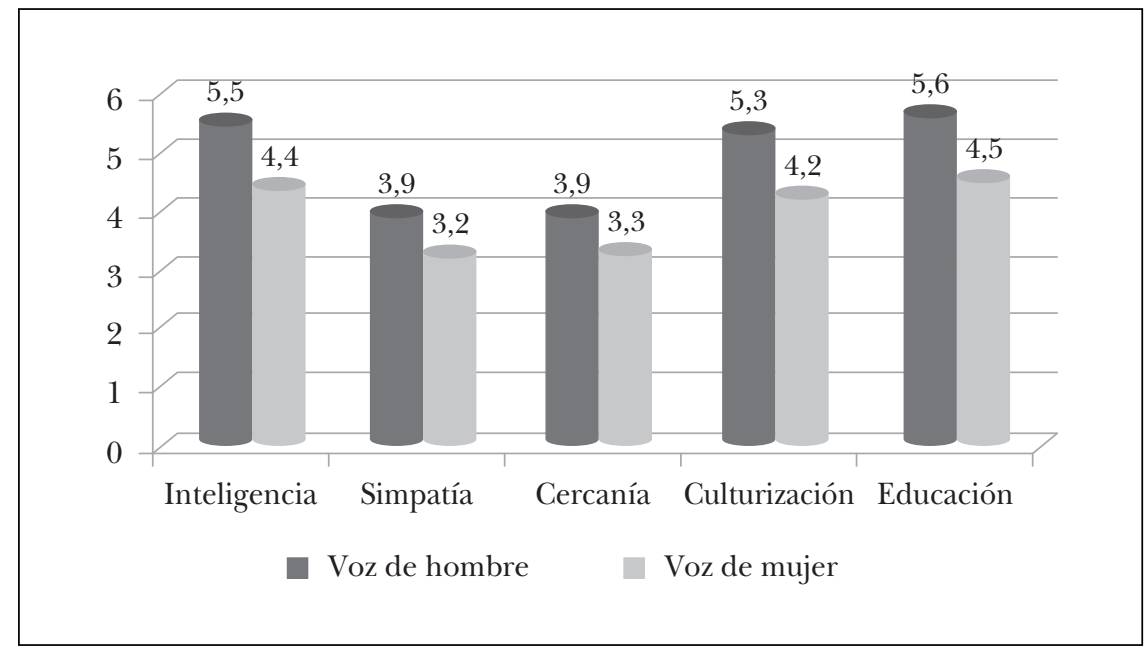


o lee, mujer, es bastante educada $(4,5)$, bastante inteligente $(4,41)$, bastante culta $(4,2)$ y cercana $(3,3)$ y simpática $(3,2)$.

$\mathrm{Y}$, de nuevo, la valoración positiva aumenta a medida que es mayor el conocimiento que los sujetos tienen sobre variedades del español, ahora con respecto a las características socioculturales (puesto de trabajo, nivel de ingreso y estudios) y personales de la persona que habla (inteligencia, simpatía, cercanía, cultura y educación).

FIGURA 9. Valoración de la variedad a través de características sociales y personales: conocimiento sobre variedades

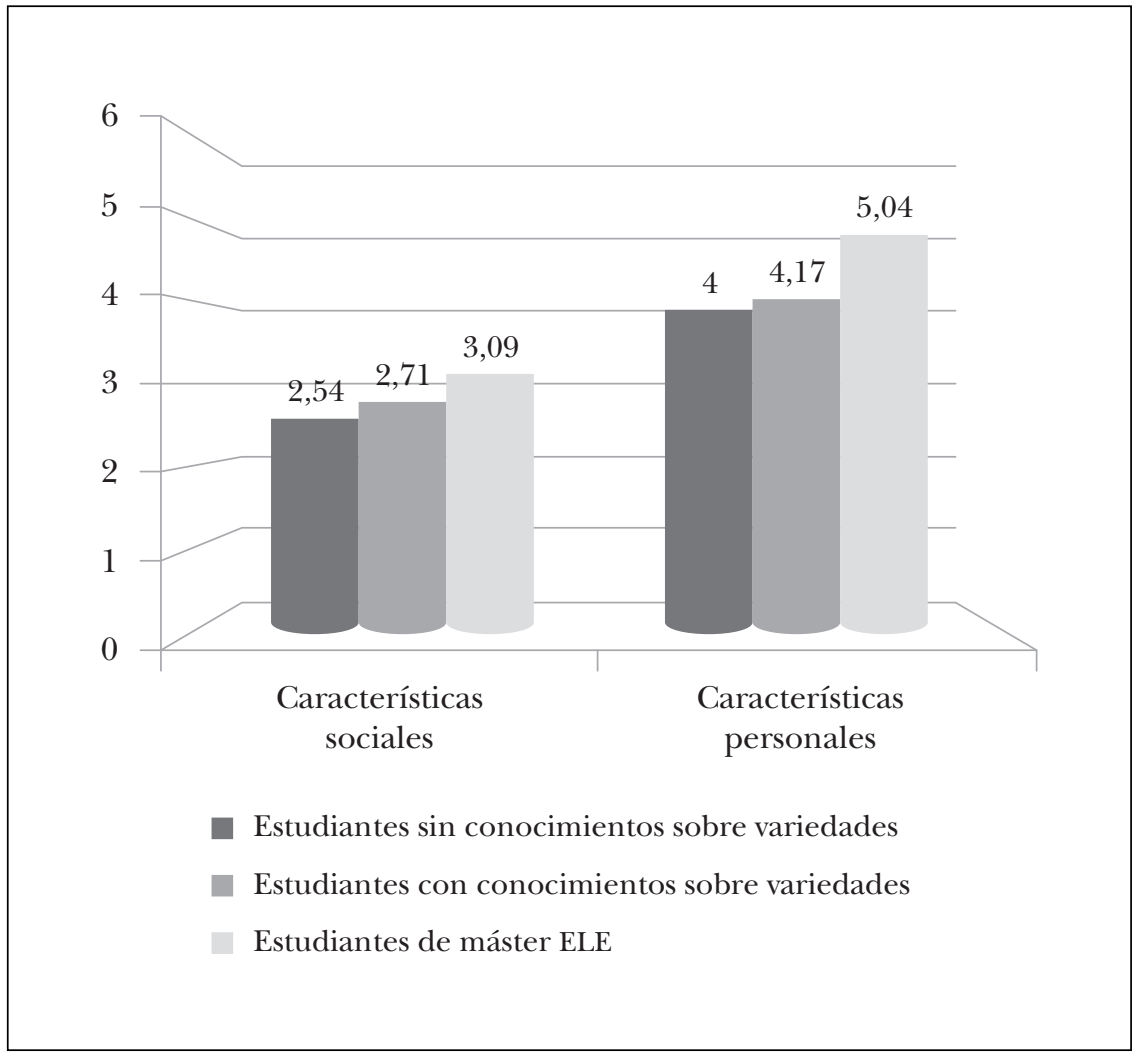

Los datos aquí ofrecidos muestran que, por las valoraciones que han hecho sobre la persona escuchada, los sujetos del centro-norte peninsular tienen creencias muy positivas sobre su propia variedad, que, ahora sí, aunque de manera indirecta, revelan que consideran la variedad prestigiosa y modélica. 


\subsubsection{Valoración de la variedad a través de la región y de la cultura}

Si atendemos a la valoración indirecta según la calificación otorgada a la región/país de la persona que habla y a su cultura, los resultados no difieren sustancialmente de los que hemos comentado en el apartado anterior, lo que apunta creencias y actitudes muy positivas hacia la propia variedad, siendo esta la centro-norteña peninsular, considerada prestigiosa e irradiadora de norma.

La valoración de la zona o el país de la persona a la que se escucha hablar, madrileña, es altamente positiva. La media obtenida en los cuatro aspectos calificados al respecto (avanzada/retrasada, divertida/aburrida, familiar/extraña y bonita/fea) es muy alta, 4,94 sobre 6 , lo que informa de una percepción bastante positiva. Tomadas por separado, todas las características apuntadas son valoradas muy positivamente, especialmente la de «bonita», que presenta una media de 5,18. En este caso, no hay una diferencia muy grande entre la calificación otorgada a partir de hablante hombre $(5,01)$ o de hablante mujer $(4,91)$. La zona de la que se cree que es el hombre que habla, centro-norte peninsular, se considera muy bonita (5,3 de media), muy familiar (5,1 de media), bastante avanzada (4,9 de media) y bastante divertida (4,6 de media). Y la zona de la que se cree que es la mujer que habla, también centro-norte peninsular, se considera muy bonita (5,1 de media), bastante familiar (4,9 de media), bastante avanzada (4,9 de media) y bastante divertida (4,6 de media).

FiguRA 10. Valoración de la variedad a través de la opinión que merece la zona

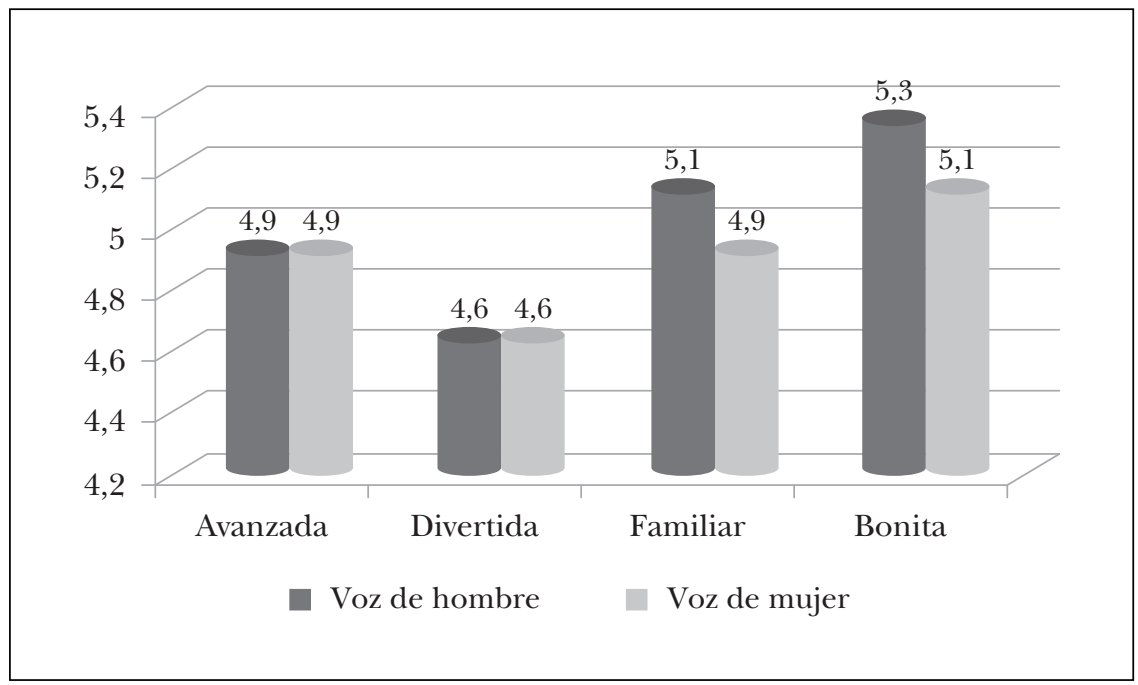


Igual de alta que en el caso anterior es la media correspondiente a la opinión de los sujetos encuestados con respecto a la cultura de su propia zona o país, 4,81 sobre 6 , lo que, de nuevo, apunta valoraciones, y, por tanto, creencias y actitudes, muy positivas hacia la variedad propia, centronorteña, ahora reveladas a través de consideraciones sobre la cultura. De manera general, los sujetos de la muestra apuntan que la cultura del centronorte peninsular es «interesante» (con una media de 5,11), «cercana» (con una media de 5,09), «rica» (con una media de 4,85) e «innovadora» (con una media de 4,19).

Las medias obtenidas indican que, en este grupo de características sobre la cultura, no se dan diferencias importantes en las valoraciones hacia la persona escuchada en atención a su sexo. Así, la media de la evaluación de voz de hombre es de 4,83 y la de voz de mujer, de 4,81; en ambos casos, se considera una cultura muy cercana y muy interesante, bastante rica y bastante innovadora.

FIGURA 11. Valoración de la variedad a través de la opinión que merece la cultura

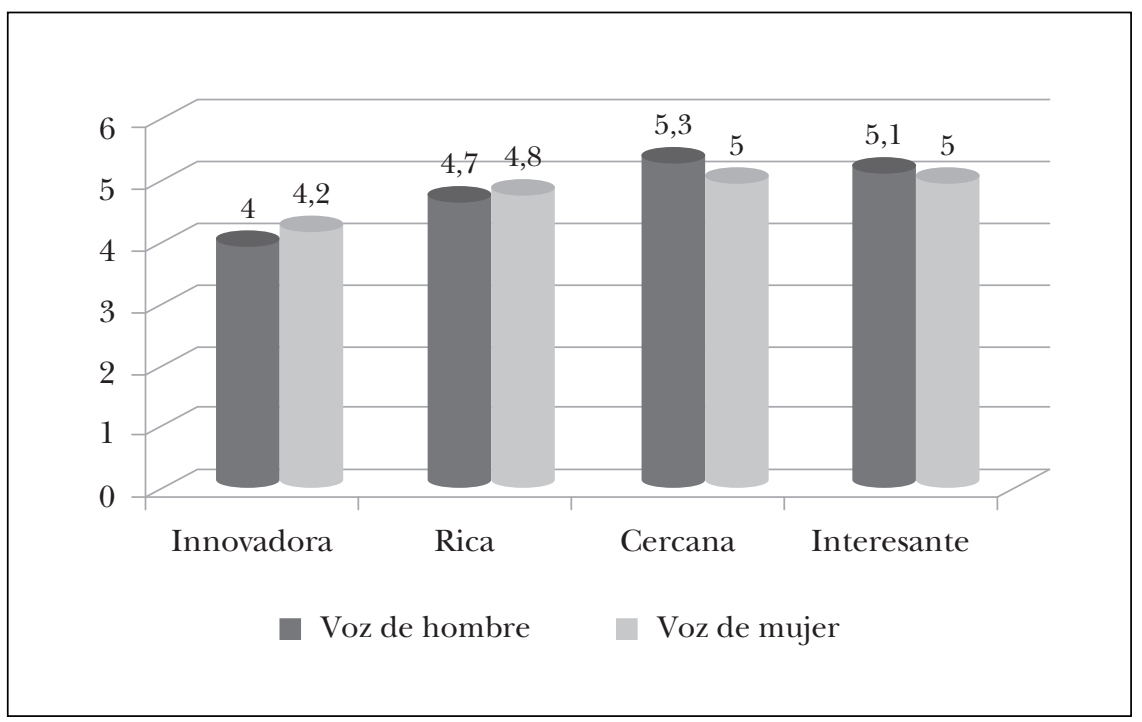

Y, una vez más, se comprueba que la valoración positiva es más alta si los sujetos tienen conocimiento sobre la existencia de variedades de una lengua, lo que relaciona directamente la percepción sobre las variedades con la instrucción específica. El gráfico 12 muestra de manera clara, además, que la valoración de la región es más positiva que la de la cultura: 
FIGURA 12. Valoración de la variedad a través de la región y de la cultura: conocimiento sobre variedades

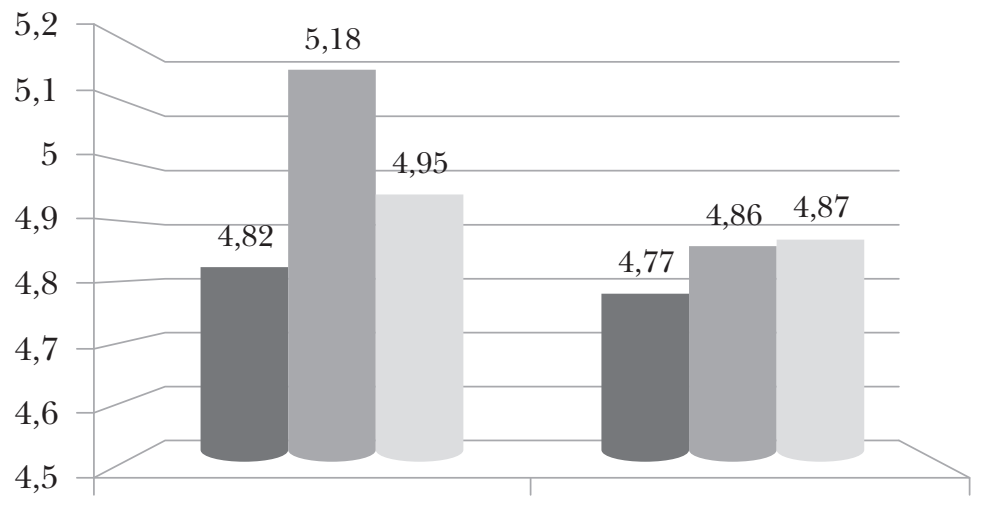

Valoración de la región Valoración de la cultura

Estudiantes sin conocimientos sobre variedades

Estudiantes con conocimientos sobre variedades

Estudiantes de máster ELE

\section{Conclusiones}

En las páginas anteriores se ha presentado el marco teórico y metodológico de un proyecto emprendido con objeto de conocer qué piensan los hispanohablantes acerca de las variedades del español en este tiempo, el Proyecto para el estudio de las creencias y actitudes hacia las variedades del español en el siglo XXI (PRECAVES XXI), así como hallazgos de interés en lo que respecta a la valoración que hacen los sujetos del centro-norte de la Península de las distintas variedades del español y a la percepción que tienen sobre su propia variedad.

Los resultados que se acaban de ofrecer son parciales, pues corresponden solo a un perfil muy específico de sujetos ${ }^{5}$ : el de quienes están más

${ }^{5}$ Como acertadamente señala un revisor anónimo de este artículo, es muy probable que los resultados y las valoraciones varíen con la ampliación de la muestra de informantes y con la inclusión en ella de diferentes niveles socioculturales o grupos de edad. Esta extensión de la muestra será precisamente el objetivo de la segunda fase del proyecto PRECAVES XXI. 
familiarizados con la diversidad dialectal del español y, por ello, son -o deberían ser- más conscientes de las repercusiones que pueden tener los estereotipos lingüísticos; las respuestas de estos encuestados del español centro-peninsular, no obstante, proporcionan datos básicos para avanzar de manera coordinada en el proyecto, ya que permitirán comparar las valoraciones obtenidas aquí con las valoraciones de ese mismo tipo de sujetos de los diferentes territorios hispanohablantes.

En relación con las creencias de los hablantes del centro y norte de la Península acerca de la variedad más prestigiosa, los datos ratifican la persistencia del estereotipo de que las diferencias entre variedades suponen una jerarquía en el grado de ejemplaridad. La autopercepción de la variedad propia es muy positiva, como demuestra el hecho de que sea la variedad castellana la considerada modelo idiomático, esto es, prototipo de lengua española. La creencia está totalmente arraigada entre los castellanoleoneses, y algo menos entre los madrileños, que se muestran más eclécticos y más permeables a admitir la primacía de otras variedades. Este conjunto de hechos refuerza la idea de que la ideología lingüística de los españoles centro-norteños es monoglósica (del Valle y Gabriel-Stheeman 2002). No obstante, esta aseveración general queda matizada si se tiene en cuenta que uno de cada tres encuestados considera la equivalencia de todas las variedades, que no se puede establecer jerarquía entre ellas a pesar de que se perciban como diferentes. Esta creencia parece aumentar con la edad y con el hecho de haber recibido formación sobre los dialectos del español, si bien no se constata adecuadamente entre quienes pretenden dedicarse a la enseñanza de ELE, colectivo en el que se hace necesario reforzar la idea de la equivalencia de variedades dialectales.

Consecuentemente con las percepciones lingüísticas descritas en el párrafo anterior, los hablantes del centro y norte de España reconocen su propia variedad y se identifican con ella. Las creencias y actitudes de estos sujetos hacia la variedad castellana, la considerada históricamente irradiadora de la norma lingüística general, son, sin duda, muy positivas, a juzgar por las valoraciones, directas e indirectas, que han hecho al contestar a las preguntas del cuestionario.

La gran mayoría de las personas encuestadas identifica correctamente la variedad castellana, que es la suya o está próxima a la suya, por lo que no es extraño que se reconozcan como usuarios de tal variedad. Este hecho podría incidir en que las valoraciones directas que hacen, aun siendo positivas, no sean muy altas, especialmente en lo que respecta a características consideradas de carácter «cognitivo», más objetivas. Sin embargo, las valoraciones indirectas son, en todos los casos, muy altas, lo que revela la consideración bastante positiva de la propia variedad, la del centro-norte peninsular, que aumenta, significativamente, cuando los sujetos tienen conocimiento específico sobre variedades del español. 


\section{BIBLIOGRAFÍA}

AJZEN, Icek (1988): Attitudes, Personality and Behaviour, Milton Keynes: Oxford University Press.

Allport, Gordon W. (1935): «Attitudes», en Carl Murchinson (ed.), A Handbook of Social Psychology, Worcester, Clark University Press. [Reproducido en Martin Fishbein (ed.) (1967): Readings in Attitude Theory and Measurement, Nueva York: John Wiley and Sons, 1-38].

Cestero Mancera, Ana María y Florentino Paredes García (2015a): «Creencias y actitudes hacia las variedades normativas del español actual: primeros resultados del Proyecto PRECAVES XXI», Spanish in Context 12/2, 255-279.

- y - (2015b): «Creencias y actitudes hacia las variedades del español en el siglo XXI: avance de un proyecto de investigación», en Dermeval da Hora, Juliene Lopes R. Pedrosa y Rubens M. Lucena (eds.), ALFAL 50 anos: contribuições para os estudos linguísticos e filológicos, Ideia: João Pessoa, 652-683.

Cestero, Ana María, Isabel Molina Martos y Florentino Paredes (2012): La lengua hablada en Madrid. Corpus PRESEEA - Madrid (distrito de Salamanca). I Hablantes de Instrucción Alta, Alcalá de Henares: Universidad de Alcalá.

Chiquito, Ana Beatriz y Miguel Ángel Quesada Pacheco (eds.) (2014): Actitudes lingüisticas de los hispanohablantes hacia el idioma español y sus variantes, Bergen Language and Linguistic Studies (BeLLS) $5<$ https://bells.uib.no/bells/issue/ view/161>.

Del Valle, José y Luis Gabriel-Stheeman (eds.) (2002): The Battle over Spanish between 1800 and 2000. Language ideologies and Hispanic intellectuals, Londres y Nueva York: Routledge, 193-216.

EDWARD, John (2011): Challenges in the Social Life of Language, Londres: Palgrave Macmillan.

Fishbein, Martin (1965): «A Consideration of Beliefs, Attitudes and Their Relationship», en Ivan D. Steiner y Martin Fishbein (eds.), Current Studies in Social Psychology, Nueva York: Holt, Rinehart \& Winston, 107-120.

GARDNER, Robert C. (1982): «Language Attitudes and Language Learning», en Ellen Bouchard Ryan y Howard Giles (eds.), Attitudes towards Language Variation, Londres: Arnold Publishers, 132-147.

- (1985): Social Psichology and Second Language Learning, Londres: Arnold Publishers.

Gómez Molina, José Ramón (1998): Actitudes lingüisticas en una comunidad bilingüe y multilectal. Área metropolitana de Valencia. Cuadernos de Filología, Anexo XXVIII, València: Universitat de València.

- (2002): «Lenguas en contacto y actitudes lingüísticas en la comunidad valenciana», en José Luis Blas Arroyo et al. (eds.), Estudios sobre lengua y sociedad, Castellón: Publicaciones de la UJI, 53-86. 
LAMbert, Wallace E. (1967): «A Social Psychology of Bilingualism», Journal of Social Issues 23, 91-108.

LAmbert, Wallace E., Robert C. Gardner, Robert Olton y Kenneth Tunstall (1968): «A Study of the roles of attitudes and motivation in second-language learning», en Joshua A. Fishman (ed.), Readings in the Sociology of Language, The Hague: Mouton, 473-491.

Lambert, Wallace E., R. C. Hodgson, Robert C. Gardner y Samuel Fillenbaum (1960): «Evaluative reactions to spoken language», Journal of Abnormal and Social Psychology 60, 44-51.

López Morales, Humberto (1979): Dialectología y sociolingüistica. Temas puertorriquenos. Madrid: Hispanova.

- (1989): Sociolingüistica, Madrid: Gredos.

- (2001): "Actitudes lingüísticas hacia el bable en la ciudad de Oviedo», Lingüistica Española Actual 23/2, 145-158.

Moreno Fernández, Francisco (ed.) (1993): La división dialectal del español de América, Alcalá de Henares: Servicio de Publicaciones de la Universidad de Alcalá.

- (1996): «Metodología del 'Proyecto para el estudio sociolingüístico del Español de España y de América' (PRESEEA)», Lingüistica 8, 257-287.

- (2000): Qué español enseñar, Barcelona: Arco/Libros.

- (2005): Principios de sociolingüistica y sociología del lenguaje, 2. ${ }^{\text {a }}$ ed., Barcelona: Ariel.

- (2009): La lengua española en su geografía, Madrid: Arco/Libros.

- (2012): Sociolingüistica cognitiva. Proposiciones, escolios y debates, Madrid/Frankfurt: Iberoamericana/Vervuert.

Moreno Fernández, Francisco y Jaime Otero Roth (2007): Atlas de la lengua española en el mundo, Barcelona: Ariel/Fundación Telefónica/Instituto Cervantes.

Osgood, Charles E., George C. Suci y Percy H. Tannenbaum (1957): The Measurement of Meaning, Chicago: University of Illinois Press. [Trad. esp. (1976): La medida del significado, Madrid: Gredos].

PRESEEA (2008): Marcas y etiquetas minimas obligatorias. Versión 1.0. 31-01-2008 $<$ http://www.linguas.net/preseea $>$.

Quintanilla, José Roberto Alexander (2012): «Esbozo de un estudio de actitudes lingüísticas en El Salvador», Revista Española de Lingüistica 42/1, 175-195.

RojAs, Darío y AvILÉs, Tania (2013): «Actitudes hacia dialectos del español usados por inmigrantes en Santiago de Chile», Boletín de Filología 48/2, 97-117.

SANCho PAScual, M. (2014): Integración sociolingüistica de los inmigrantes ecuatorianos en Madrid, Alcalá de Henares: Servicio de Publicaciones de la Universidad de Alcalá.

WiLliams, F. (1974): «The Identification of Linguistic Attitudes», International Journal of the Sociology of Language 3, 21-32.

Yraola, A. (2014): «Actitudes lingüísticas en España», en A. B. Chiquito y M. Á. Quesada Pacheco (eds.), Actitudes lingüisticas de los hispanohablantes hacia el idioma español y sus variantes, Bergen Language and Linguistic Studies (BeLLS) 5 $<$ http://dx.doi.org/10.15845/bells.v5i0.685>. 